https://artnodes.uoc.edu

\title{
Jugabilidad asíncrona. Los rasgos del videojuego en el cine experimental y la videocreación
}

\author{
Albert Alcoz \\ Universidad de Barcelona
}

Fecha de presentación: octubre de 2021

Fecha de aceptación: diciembre de 2021

Fecha de publicación: enero de 2022

\section{Cita recomendada}

Alcoz, Albert. 2022. "Jugabilidad asíncrona. Los rasgos del videojuego en el cine experimental y la videocreación». Artnodes, no. 29. UOC. [Fecha de consulta: dd/mm/aa]. https://doi.org/10.7238/ artnodes.v0i29.393101

\section{Resumen}

Existen numerosas obras audiovisuales creadas por cineastas y videoartistas que anticipan recursos visuales y propuestas conceptuales aplicados posteriormente al ámbito de los videojuegos. El cine experimental y la videocreación no solo influyen en la implementación de estrategias estéticas y narrativas introducidas en la cultura del videojuego, sino que también son permeables a esta. Así, diversos juegos de ordenadores, máquinas de arcade y videoconsolas sirven como inspiración para realizar piezas videográficas que problematizan los usos y abusos de una industria en auge constante. Reflexionar sobre la idiosincrasia de esta conexión bidireccional es el propósito de un texto que pone en juego el valor de una serie de intercambios perceptibles en ambas disciplinas. De este modo, se estudian los inicios de la creación de imágenes por computadora (CGI) en diálogo con la animación abstracta; el carácter interactivo de los videojuegos en consonancia con videoinstala- 
ciones coetáneas; los juegos de simulación y los first-person shooter (FPS), junto al punto de vista subjetivo en las prácticas fílmicas de vanguardia; el reciclaje de imágenes digitales extraídas de videojuegos de acción en el género de la machinima y la radicalidad de los discursos políticos presentes en los artists' game mods. Estos son los apartados explorados en un texto que propone un acercamiento transversal al mundo del videojuego, dejando de lado el cine de ficción para concentrarse en el cine experimental y la videocreación. Abordar las similitudes formales e ideológicas que estos últimos tienen con el universo virtual del videojuego son objetivos prioritarios de un artículo que constata el carácter asíncrono de estas influencias. Observar cómo este intercambio incrementa exponencialmente alcanzada la era digital es un signo del fructífero devenir que supone este encuentro.

\title{
Palabras clave
}

videojuego; cine experimental; videoarte; animación por ordenador; interactividad; machinima

\section{Asynchronous gameplay. The features of the videogame in experimental cinema and video creation}

\begin{abstract}
There are numerous audiovisual works created by filmmakers and video artists that anticipate visual resources and conceptual proposals later applied to the field of video games. Experimental cinema and artists video not only influence the implementation of aesthetic and narrative strategies introduced in video game culture but are also permeable to it. Thus, various computer games, arcade machines, and video consoles serve as inspiration to create videographic pieces that problematize the uses and abuses of an industry undergoing constant growth. Reflecting on the idiosyncrasy of this bidirectional connection is the purpose of a text that puts into play the value of a series of perceptible exchanges in both disciplines. In this way, the beginnings of computer-generated images (CGI) are studied in dialogue with abstract animation; the interactive nature of videogames in line with contemporary video installations; simulation games and first-person shooter (FPS) together with the subjective point of view in avant-garde film practices; the recycling of digital images extracted from action videogames in the genre of machinima and the radicality of the political discourse present in the artists' game mods. These are the sections explored in a text that proposes a transversal approach to the world of videogames, leaving fiction cinema aside to focus on experimental cinema and video creation. Addressing the formal and the ideological similarities that the latter share with the virtual universe of the videogame are important objectives of an article that confirms the asynchronous nature of these influences. Observing how this exchange increases exponentially once the digital age has been reached is a sign of the fruitful evolution that this meeting supposes.
\end{abstract}

\section{Keywords}

video game; experimental cinema, video art, computer animation, interactivity, machinima 


\section{artnodes}

\section{Introducción}

Proponer un recorrido por el intercambio de influencias generado entre dos disciplinas artísticas como el cine experimental y el videojuego es el propósito de este texto. Ambas áreas presentan un buen número de similitudes formales, conexiones conceptuales y principios ideológicos susceptibles de examinarse desde la historia de las artes visuales, el arte digital y los nuevos medios. Contextualizar los principios de cada ámbito, definiendo el avance sistemático de sus tecnologías, demuestra cómo estas dos dimensiones recreativas elaboran sinergias desde mediados del siglo xx hasta inicios del nuevo milenio. Después de establecer un marco teórico que intuye el influjo constante entre la experimentación audiovisual y el mundo de los videojuegos, el artículo analiza una serie de conceptos que implican ambas artes: CGI (computer-generated images), interactividad, simulación, FPS (first-person shooters), machinima y artists' game mods. Las cuestiones narrativas del cine de ficción susceptibles de entreverse en el videojuego (Bogost 2007), así como la radicalidad formal y conceptual de los videojuegos de vanguardia (Schrank 2014), son ámbitos que se han dejado de lado para acotar el objeto de estudio exclusivamente en prácticas artísticas audiovisuales. Sí que se han tenido en consideración tanto análisis panorámicos sobre la incidencia del diseño de videojuegos en ámbitos sociales y culturales (Salen y Zimmerman 2003), como estudios interdisciplinares que detectan las conexiones entre la esfera de los videojuegos y el ámbito de las artes visuales (Clarke y Mitchell 2007/2013).

En cada bloque se analizan filmes, vídeos e instalaciones que evidencian coincidencias estéticas, afinidades semánticas y similitudes epistemológicas con la cultura del videojuego desde su gestación hasta su consolidación. El artículo se concentra así en trabajos artísticos que anticipan desarrollos gráficos, perspectivas visuales y posibilidades interactivas implementadas posteriormente en videojuegos. Del mismo modo, también contempla el reciclaje y la modificación de sonidos e imágenes de juegos de arcade, consolas u ordenadores por parte de artistas visuales. Proponer poéticas insólitas y discursos críticos punzantes son acciones que contrarrestan el poder de la industria del entretenimiento con su ímpetu por la espectacularidad y la homogeneidad. Interrogar la cultura gamery problematizar el relevante papel que ocupa en el paisaje mediático actual resulta prioritario para numerosos artistas que deciden incorporar su iconografía y su tecnología para ofrecer otras miradas.

En 2007, los teóricos Gilles Lipovetsky y Jean Serroy afirman categóricamente que «es evidente que el universo videolúdico no se parece al del cine. En el primero, el placer depende de las decisiones, del dominio, de la acción "eficaz", mientras que en el segundo priman la mirada y la atención expectante a un relato que no se puede cambiar» (288). Por su parte, el teórico y cineasta inglés Malcolm LeGrice, reflexionando en 1997 sobre la importancia de las nuevas tecnologías digitales para la consecución de un cine interactivo, acude simultáneamente al cine experimental y a los juegos de ordenador: «En la búsqueda de enfoques alternativos, conjugando la estructura artística con las nuevas posibilidades tecnológicas, existen dos fuentes que ofrecen posibilidades de dar buenos resultados: la gramática cinematográfica desarrollada por el cine experimental (o de vanguardia), el cual se ha resistido, ha transformado 0 ha creado vías alternativas a la narración lineal; y, posiblemente más sorprendente, el juego de ordenador» $(1997,48)$.

El cine y el vídeo experimental siempre han sido un terreno apto para la exploración visual y sonora; la permanente búsqueda de configuraciones radicales es uno de sus rasgos característicos. Entrados los años sesenta, la experimentación cinematográfica se expande en múltiples líneas de fuga: instalaciones fílmicas, multiproyecciones, tecnología videográfica, videoinstalaciones, imagen por computadora, etc. Denominada expanded cinema por el teórico Gene Youngblood en su libro homónimo, esta explosión de dispositivos tecnológicos -junto a una expansión de la consciencia- fomenta la existencia de películas computarizadas, cine sinestésico, holográfico y cibernético (Youngblood 1970). Son manifestaciones sustentadas en la libertad expresiva que ponen en juego tanto estrategias narrativas no lineales como opciones de interacción con la audiencia. Al usar el término cine experimental nos concentramos en aquellas películas realizadas en soporte filmico (generalmente en $16 \mathrm{~mm}$ ), alejadas de los cánones de la industria audiovisual, pero también referenciamos todo este otro escenario multivisual. Cuando empleamos la noción de videocreación o videoarte nos referimos a aquellas obras que usan tecnología videográfica bajo presupuestos estéticos y cognitivos desplegados exclusivamente en espacios artísticos.

Los videojuegos pueden definirse como juegos electrónicos creados para fomentar la interacción de jugadores mediante un dispositivo tecnológico regido por una interfaz (teclado, joystick, ratón, máquina recreativa, etc.) y una pantalla donde se despliegan efectos visuales y sonoros. Estos se comercializan a inicios de los años setenta, pero su consolidación no se produce hasta entrados los años ochenta, cuando se popularizan las máquinas de salón recreativo y las videoconsolas de uso privado (Lebihan 2018). A las pantallas de los juegos arcade y los ordenadores personales (Atari, Amiga, Spectrum, Amstrad, Commodore, etc.) se les suman las consolas portátiles y aquellas otras conectadas a televisores (Nintendo, Sega). El crecimiento de esta industria se produce gracias a internet y el éxito de modalidades como los RTS (real-time strategy) o los MMORPG (massively multiplayer online role playing game). El último episodio relevante respecto a la explosión de la jugabilidad virtual vendría dado tanto por la omnipresencia de pantallas móviles en teléfonos inteligentes como por las retransmisiones masivas de competiciones online vía plataformas como Twitch.

Aunque la influencia recíproca entre la experimentación audiovisual y la creación de videojuegos haya recibido escasa atención, sí que ha asomado con fuerza la noción de game art, un concepto que acerca la cultura del videojuego al arte contemporáneo. El término puede crear controversia porque asume la infiltración de parámetros lúdicos e interactivos propios de la industria del entretenimiento a 
unos contextos artísticos regidos por convenciones culturales que legitiman las propuestas estéticas expuestas. John Sharp afirma que este fenómeno «no es un movimiento en sí mismo, sino un grupo de artistas visuales no afiliados que utilizan los juegos para hacer obras de arte» $(2015,22)$. Detectar constantes estéticas identificables en prácticas no sometidas a requerimientos narrativos ni imposiciones presupuestarias es uno de los objetivos prioritarios de los apartados siguientes. Es por ello por lo que se convocan cortometrajes de animación hechos por ordenador, piezas fílmicas breves producidas en 16 $\mathrm{mm}$, obras de videocreación y videoinstalaciones que especulan otras modalidades de interactividad.

Metodológicamente, la selección de las piezas escogidas en el artículo responde a criterios cualitativos. Los trabajos aquí reunidos son ejemplos de trayectorias artísticas contrastadas que vislumbran iconografías posteriormente implementadas en gráficos de videojuegos o recuperan tratamientos visuales de algunos de estos juegos para generar otro tipo de mensajes, generalmente críticos. El texto propone un marco temporal delimitado. ya que especifica las sinergias producidas desde la aparición de los videojuegos durante la década de los setenta hasta el año 2010. Ante la proliferación de obras de videocreación de esta última década que incorporan imaginería extraída de videojuegos, se ha optado por acotar el objeto de estudio a este parámetro temporal.

\section{CGI: animación abstracta y videojuegos minimalistas}

La mayoría de los videojuegos proponen adentrarse en un mundo ficticio sustentado en la ilusión de realidad. Para que esto sea posible, la verosimilitud en el tratamiento de los gráficos resulta ineludible. Durante los primeros años de desarrollo de imágenes generadas por computadora (CGI) la simplificación gráfica es uno de sus rasgos característicos. Las limitaciones tecnológicas condicionan las imágenes resultantes; un ejemplo de esto sería PONG (1972), el primer exponente de videojuego ball and paddle. En este contexto, la creación de imágenes por ordenador dialoga con otra área de mayor trayectoria: la animación abstracta. John Whitney, Lillian Schwartz, Stan Vanderbeek y Manfred Mohr son artífices de las primeras películas creadas con ordenadores a finales de los años sesenta. Sus conocimientos técnicos dan como resultado piezas minimalistas de formas sencillas que se desenvuelven de modo sintético. Es un cine electrónico que explora las posibilidades creativas de unas herramientas limitadas, un cine de animación no objetivo que recoge la tradición de la música visual. Según Ann-Sargent Wooster, «la participación continua de los videoartistas en la exploración de aquello que pueden producir las máquinas ha llevado a la reciente fascinación por tecnologías de alta gama como gráficos por computadora, efectos especiales y edición, y experimentos actuales con video discos interactivos» $(1990,286)$.
En Special Effects (1972) el cineasta norteamericano Hollis Frampton reduce toda representación visual a un espacio negro enmarcado por líneas blancas discontinuas (Figura 1). Este recuadro vibra al son de una banda sonora hecha de bleeps electrónicos cuyos sonidos evocan los emitidos por videojuegos como Spacewar! (1962) y Space Invaders (1978), dos clásicos del género de matamarcianos (shoot'em up o STG). En Calculated Movements (Larry Cuba 1982-85) decenas de formas alargadas se desplazan sobre un fondo oscuro, apareciendo y desapareciendo al son de texturas ruidosas (Figura 2). Tanto el dibujo geométrico blanquecino que emerge de la superficie como el recorrido que establece -movimientos horizontales, verticales y diagonales- recuerdan la estética de un videojuego tan popular como Snake (1976). Este construye su jugabilidad sobre la base de una serpiente que incrementa su longitud a medida que captura puntos distribuidos por la pantalla. Su simplicidad viene motivada por imposiciones tecnológicas porque no necesita de un número extremadamente elevado de píxeles; el éxito de la versión que la empresa Nokia comercializa para móviles en 1998 reafirma esta idea. Cubica (m.ash 2002) perfila con herramientas digitales las posibilidades que se amagan tras formas geométricas. El vídeo, de poco más de cuatro minutos, parte de unos pocos píxeles que modifican su apariencia, complicándola a medida que avanza por un entorno tridimensional generado por algoritmos. El artista austriaco Michael Aschauer (m.ash) introduce la ilusión de profundidad prolongando unos gráficos cuya apariencia imagina una versión volumétrica y cenital del popular Tetris (1984), con su reiterativo encaje de piezas.

Si las constricciones tecnológicas de los primeros ordenadores fomentan la inventiva para crear piezas de animación abstracta, el potencial de la imagen digital del nuevo milenio permite recurrir a soluciones gráficas del pasado para reconfigurarlos. Estos trabajos introducen gráficos sencillos resueltos de modo informático, adscribiéndose así a la noción de cine calculado (Bonet 1999).

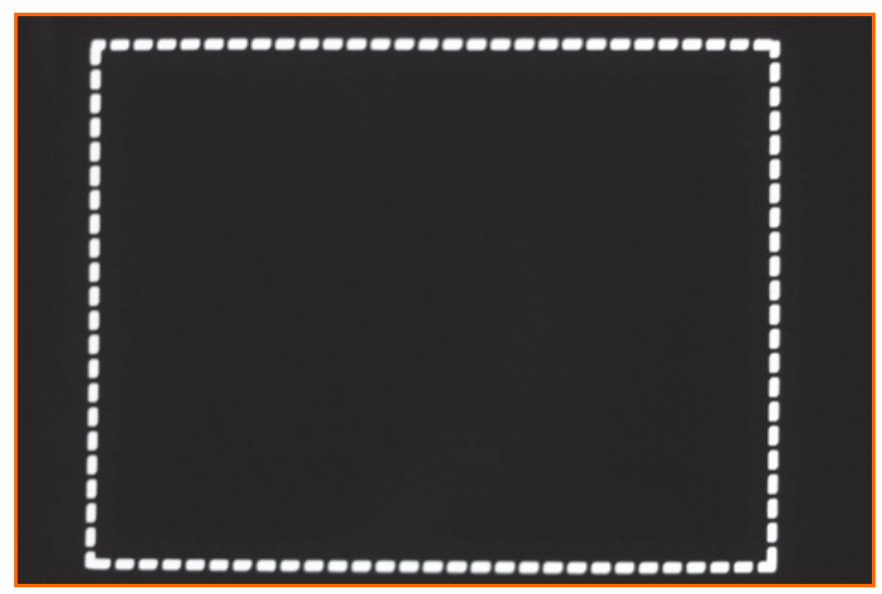

Figura 1. Special Effects (Hollis Frampton 1972)

Fuente: @Anthology Film Archives 


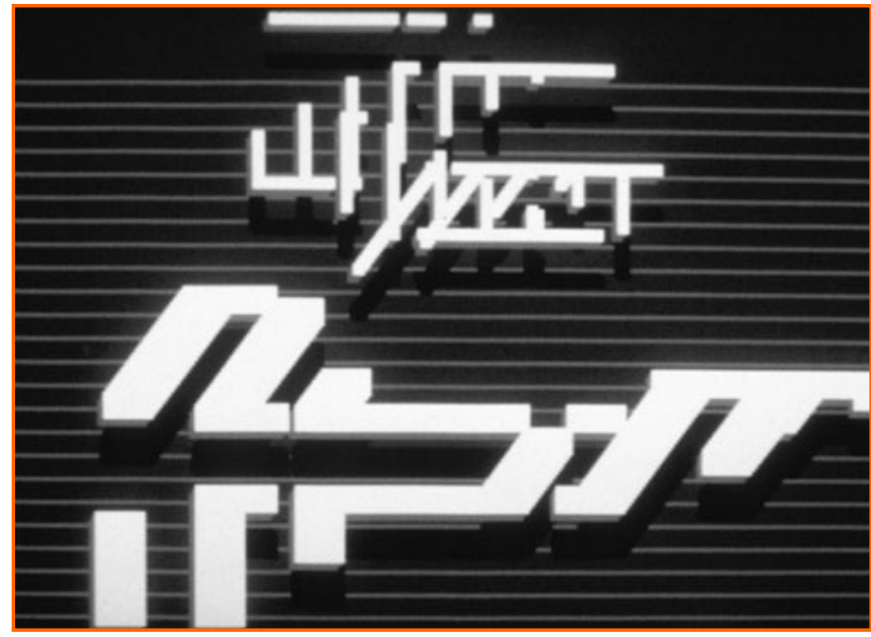

Figura 2. Calculated Movements (Larry Cuba 1982-85)

Fuente: @Larry Cuba

\section{Interacción: videoinstalaciones y máquinas arcade}

El ámbito de la videoinstalación es un terreno propicio para testear la interacción con la audiencia. Varios factores fomentan la relación directa entre espectadores y piezas de materiales heterogéneos acogidas por centros de arte. Las instalaciones de videocámaras en circuito cerrado demandan la acción de aquellas personas que las observan para poder activarse. Este tipo de interacción se congrega mediante cámaras en directo, sensores y otros dispositivos que responden ante las variaciones del entorno. Dan Graham, Bruce Nauman y Peter Campus crean videoinstalaciones que sitúan al espectador en el centro de la pieza, lo que da lugar a propuestas metalingüísticas. Para Peter Weibel, «(...) videoinstalaciones con circuito cerrado de televisión, ciberespacio, videoinstalaciones interactivas, mundos virtuales y otros tipos de Media Art participativos, interactivos y dependientes del observador son formas prototípicas de una imagen de mundo activada técnicamente, en la cual siempre somos parte del sistema que observamos y con el que interactuamos» (1995, 19-20). Las diferencias entre el carácter unidireccional del cine y las opciones multicursales de ciertas videoinstalaciones plantean paralelismos con el contraste entre los juegos lineales y los Sandbox, con su amplia libertad de movimientos.

Sensorama (Morton Heilig 1957-1962) es una de las primeras experiencias de interacción física con imágenes en movimiento. Este aparato inmersivo introduce una tecnología que está considerada uno de los pasos iniciales para el desarrollo de la realidad virtual (RV). Una pantalla estereoscópica a color con cinco películas en 3D, un sistema sonoro estéreo, una silla en vibración, emisores de olores y un ventilador son los elementos usados para simular un recorrido motorístico por las calles de Brooklyn (Nueva York). Impresiones táctiles, olfativas, visuales y acústicas conforman una experiencia que simula una variedad de estímulos multisensoriales y motrices, sin moverse de un mismo lugar. Centenares de máquinas arcade posteriores, con sus videojuegos de simulación, perfeccionan este prototipo enfatizando impresiones visuales y sonoras. The Legible City (Jeffrey Shaw 1989) es una instalación interactiva en la que el visitante se monta sobre una bicicleta estática para recorrer el trazado de una ciudad formada por palabras (Figura 3). Los planos de Manhattan, Ámsterdam y Karlsruhe son la materia prima a partir de la cual Shaw desarrolla el diseño tipográfico de textos seleccionados de Dirk Groeneveld. El viaje virtual por las calles de estas tres ciudades simula trayectos en los que la lectura toma sentido pedaleando. La interfaz se convierte en algo paródico en manos de la estadounidense Mary Flanagan. Con su proyecto [giantJoystick] (2006) replica el joystick del modelo de Atari 2600 de 1980 en una escultura de casi tres metros de altura (Figura 4). Así, la artista visual, creadora y teórica de videojuegos explora la noción de colaboración grupal a través de un joystick sobredimensionado con el que los visitantes pueden entretenerse con juegos como Asteroids (1979). Esta videoinstalación transgrede la jugabilidad habitual incrementando la escala del software, lo que da lugar a un aparato que recuerda a artefactos de espacios recreativos infantiles. Osmose (Char Davies 1994-1995) es una instalación inmersiva centrada en el diseño de un entorno desplegado exclusivamente para gafas de RV. Aquí el cuerpo del visitante promueve las modificaciones de los ambientes gráficos. El software responde a la respiración y el equilibrio del usuario de modo que la persona interactúa con un espacio inmersivo que desafía la noción de gravedad.

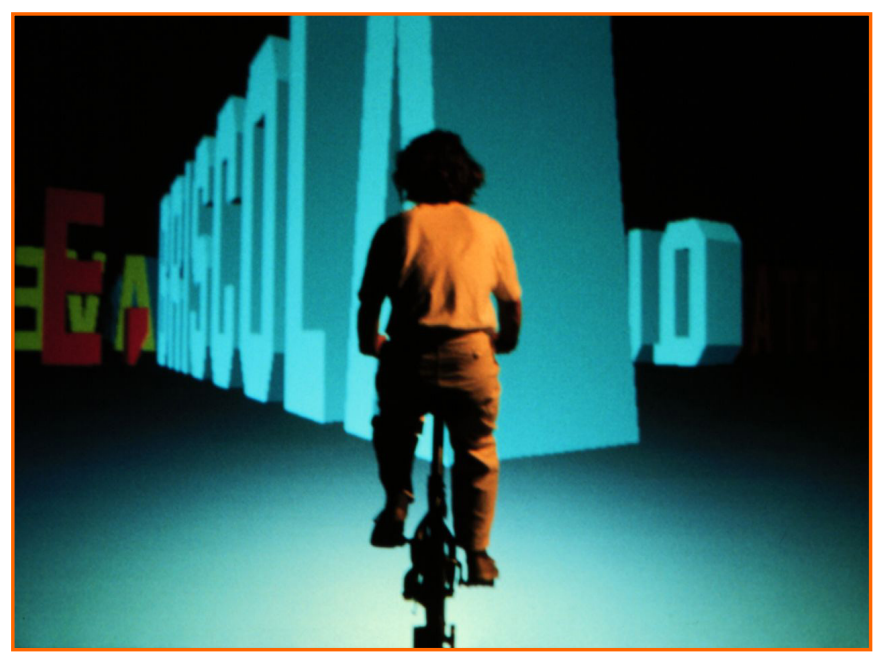

Figura 3. The Legible City (Jeffrey Shaw 1989)

Fuente: @Jeffrey Shaw

Si la bicicleta de Shaw imagina la posibilidad de leer circulando sobre ruedas, el joystick de Flanagan amplía la jugabilidad implicando todo el cuerpo, aspecto que la compañía Nintendo introduce en 2006 
mediante su videoconsola doméstica Wii. Por su parte, la creación de ambientes imaginarios de Davies rememora aquellos desarrollados previamente en versiones de RPG (role playing games), aventuras gráficas como Zelda (1986), Dragon Quest (1986) o Final Fantasy (1987).

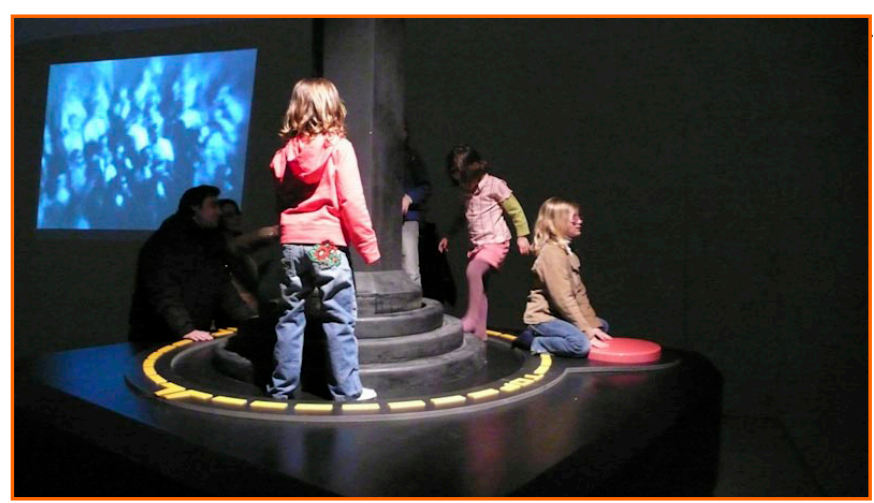

Figura 4. [giantJoystick] (Mary Flanagan 2006) Fuente: @Mary Flanagan

\section{Punto de vista subjetivo: experimentación fílmica, FPS y simuladores}

En las obras cinematográficas, el punto de vista subjetivo permite incrementar el grado de identificación del espectador con el protagonista. Son diversos los trabajos teóricos que estudian el plano subjetivo fílmico -aquello observado por los intérpretes en la diégesis- para hallar concordancias con la visualización de los first-person shooters. En opinión de Alexander R. Galloway, «(...) los videojuegos son tremendamente diversos en su gramática formal, pero en los juegos conocidos como FPS (videojuego de disparos en primera persona), un género inventado en la década de 1970 y perfeccionado por Id Software a principios de la década de 1990 con juegos como Wolfenstein 3D y Doom, hay varias convenciones formales que aparecen una y otra vez» $(2006,57)$.

Oh! I Can't Stop! (Zbigniew Rybczynski 1976) es un cortometraje de diez minutos que construye su lógica a partir de un punto de vista subjetivo del que se desconoce el cuerpo protagonista. Anticipa representaciones FPS como Quake (1996) sin la necesidad de incorporar arma ni disparos, tan solo un avance fulgurante en un entorno tridimensional. Los efectos sonoros sugieren la presencia de un ser ruidoso que genera miedo y desconcierto a su alrededor; los gritos de las personas con las que se cruza revelan la amenaza de su presencia. Su desplazamiento anticipa videojuegos cuya lógica consiste en avanzar impetuosamente, superando situaciones adversas. Los simuladores de vuelo, automóvil y otros transportes también incorporan el recurso del travelling frontal bajo un punto de vista subjetivo como eje vertebrador de su jugabilidad. En cierto modo, estos simuladores remiten a aquellos filmes del cine de atracciones ensimismados en capturar desplazamientos continuos (Gunning 1990). En C'était un rendezvous (Claude Leduch 1976) se observa una calle de la ciudad de París capturada a primera hora de la mañana desde un plano inferior ligeramente contrapicado (Figura 5). El rugido del motor de un coche de gran cilindrada y el travelling frontal sugieren que la cámara cinematográfica ha sido colocada delante de un automóvil. A lo largo de ocho minutos se muestra un plano secuencia del recorrido de un vehículo que circula por la ciudad a gran velocidad, sin respetar señales de tráfico ni normas de circulación. Adelantando coches de modo imprudente, saltándose una decena de semáforos en rojo y generando múltiples situaciones de peligro, el film documenta una acción real llevada a cabo por el propio cineasta francés. Leduch presagia muchos videojuegos de coches de carreras ensimismados en la impunidad de la velocidad. Autosong (1976) de Al Jarnow se construye a partir de una serie de dibujos figurativos que representan la conducción de un vehículo por una carretera minimalista y repetitiva. Esa reiteración de los paisajes y el encuadre que imita el punto de vista de su conductor son características que remiten al diseño de videojuegos de los primeros tiempos como es el caso de Pole Position (1982), un juego de Fórmula 1 creado por la empresa Namco. Por otro lado, un largometraje como Unidivided Attention (1987) del cineasta canadiense Chris Gallagher -con su plano recurrente de un conductor y su pareja, capturados desde la parte trasera de un coche descapotable en circulación (Figura 6) - remite a la tipología de planos de simuladores de conducción como Out Run (1986) o Gran Turismo (1998).

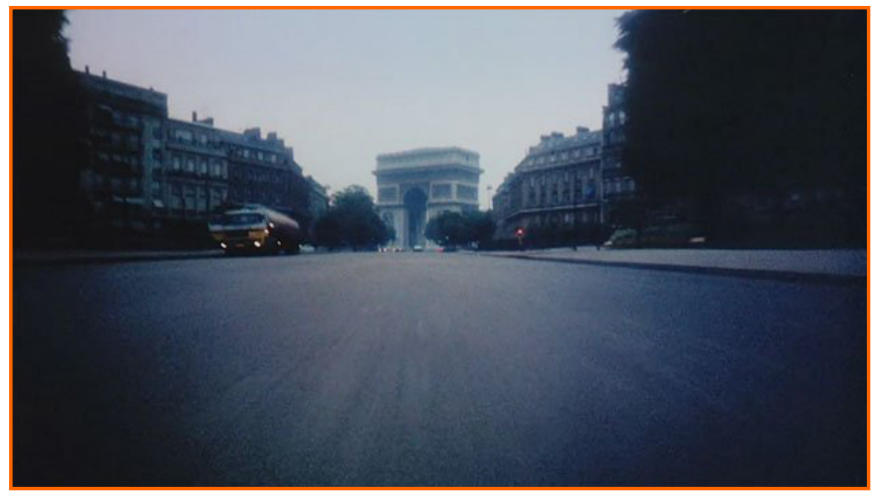

Figura 5. C'était un rendezvous (Claude Leduch 1976)

Fuente: @Claude Leduch

Estas películas plantean soluciones visuales que los videojuegos perfeccionan profundamente pocos años después. El desplazamiento univiario de los filmes contrasta con el carácter multiviario de juegos construidos en función de un amplio abanico de posibilidades itinerantes. Si las películas mencionadas pueden verse como precedentes de juegos FPS y simuladores automovilísticos, no es menos cierto que 
recursos fílmicos como ese impetuoso avance frontal hasta el final muestra similitudes con la estética de los videojuegos.

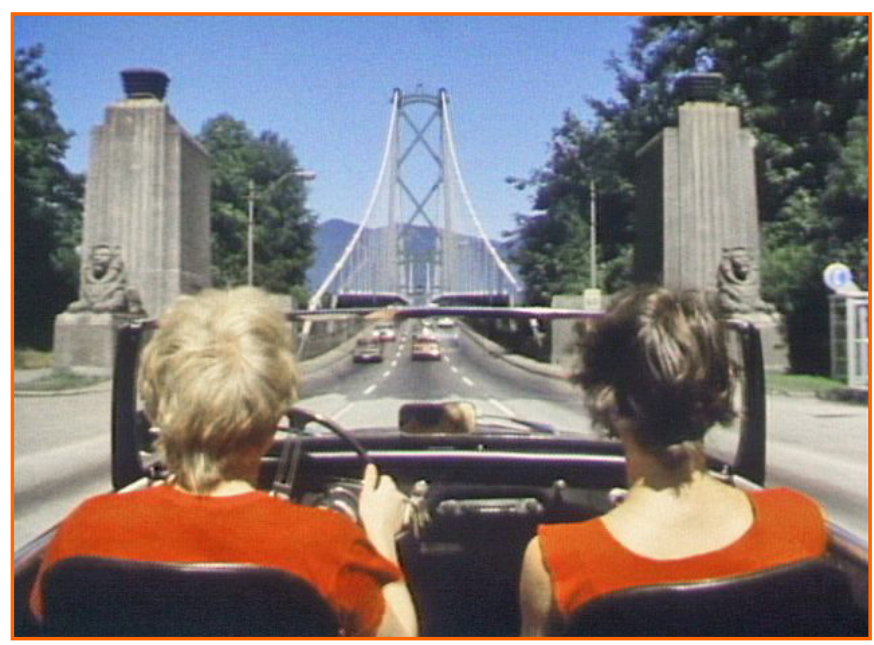

Figura 6. Unidivided Attention (Chris Gallagher 1987)

Fuente: @Chris Gallagher

\section{Reciclaje audiovisual: found footage y machinima}

La palabra machinima es una contracción de los términos «machine» (máquina) y «cinema» que un colectivo de cineastas denominados The Strange Company acuñan a finales de los años noventa. Si inicialmente el término identifica vídeos realizados para fomentar el uso de videojuegos, posteriormente sirve para detectar vídeos narrativos (texto, voz en off) que reciclan imágenes de videojuegos. Estas grabaciones manipulan contenido visual y sonoro de productos previos con la intención de generar obras paródicas o poéticas que siguen la tradición del cine de apropiación o de found footage (Wees 1993). Así, estos artistas cuestionan el poder de atracción de los videojuegos fomentando lecturas críticas. En palabras de Elijah Horwatt, «en lugar de apropiaciones cinematográficas, la machinima emplea entornos, avatares, historias de fondo e incluso secuencias pre-renderizadas digitalmente apropiadas» $(2007,8)$. Son piezas de videocreación que tergiversan los videojuegos apropiados, planteando formas de resistencia mediática con gestos disruptivos. Según Pau Alsina, «la apropiación y la recontextualización artística de videojuegos viene de lejos; por ejemplo, con fenómenos como el game modding (personalización de juegos) y el game patching (parcheado de juegos) de los usuarios» $(2007,2)$.

En She Puppet (Peggy Ahwesh 2001) la protagonista femenina Lara Croft se rebela contra su misión y su condición de personaje manipulable. A través de imágenes reeditadas de este videojuego de acción, la estadounidense pone en duda la identidad y la mortalidad de su avatar (Figura
7). Las voces en off de Yuko Armaki, Samuel Topiary y Eva Waniek recitan reflexiones de Fernando Pessoa, Joanna Russ y Sun Ra mientras un montaje de planos dispares visualizan, entrecortadamente, la particularidad del juego. Croft fallece múltiples veces, cayendo al suelo de rodillas, mientras emite un grito de dolor en una serie de finales de partida de resonancias existenciales. She Puppet cuestiona un producto dirigido al público masculino poniendo en duda la idealización del cuerpo femenino. En Vietnam Romance (2003) el artista norteamericano Eddo Stern amalgama una serie de fragmentos de videojuegos de ordenador que tienen la guerra de Vietnam como escenario. Un discurso feminista, combativo e insistente, recitado por Jessica Hutchins, elucubra nuevas posibilidades teóricas para imágenes. Rehearsals for Retirement (Phil Solomon 2007) parte de imágenes extraídas del videojuego Grand Theft Auto (1996) para elaborar un cortometraje existencialista hecho de múltiples capas. Entornos difuminados, borrosos y vaporosos de una metrópolis llamada Liberty City son el escenario de una pieza de doce minutos protagonizada por un avatar musculoso totalmente pasivo. Se aprecia un tono misterioso que aumenta gracias a una banda sonora de instrumentación clásica progresivamente dramática. My Trip to Liberty City (2005), del canadiense Jim Munroe, parte de Grand Theft Auto III (2001), en este caso para tratar de evitar todo conflicto y comportarse como un buen ciudadano.

Contrarrestar la fascinación que producen los motivos visuales de Ios materiales originales, implicando una postura radical respecto a su poder de influencia, es un propósito de artistas audiovisuales que elaboran vídeos de creación en los que la contemplación y la reflexión son respuestas a la acción desenfrenada de los materiales originales.

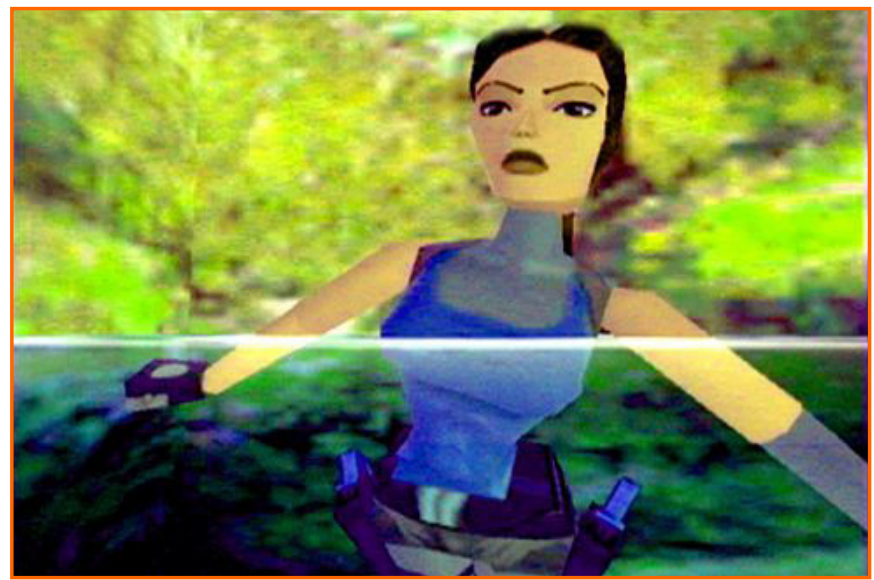

Figura 7. She Puppet (Peggy Ahwesh 2001)

Fuente: @Peggy Ahwesh

\section{Apropiación: hackeo y artists' game mods}

Son diversos los artistas que modifican los sistemas tecnológicos de videojuegos para enfatizar aspectos concretos de su universo representacional. Escenarios 
diseñados inicialmente para describir universos virtuales son manipulados -vía shareware - 0 apropiados -vía software- para convertirse en información gráfica subvertida. Sus artífices -autodenominados hackers- recuperan el espíritu activista del détournement situacionista y el culture jamming contrarrestando la cultura masiva del videojuego. Valga como ejemplo ilustrativo Ars Doom (Orhan Kipcak y Reini Urban 1995), que parte del «engine» de Doom II para introducir una serie de referencias pictóricas propias de la alta cultura (Arnulf Rainer, Georg Baselitz). Según Jemima Rellie son modificaciones que «implican una reformulación de la cultura popular por parte de los artistas (...) para transformarla en una forma elevada de arte modificando el contenido y "hackeando" el juego mismo con el objetivo de alterar la percepción del público» $(2007,56)$. Oponiéndose al mainstream, estas modificaciones tienen lugar en contextos artísticos que, normalmente, obstaculizan cualquier intento de interacción. Entorpecer la jugabilidad o impedir cualquier opción de interactividad con los dispositivos promueve otro tipo de lógica para el videojuego, una que se detiene en su base conceptual por encima de su aplicación práctica. A menudo, generan frustración por la escasa fluidez de su navegación. El elogio del glitch es otro de los factores habituales en manifestaciones como Adam Killer (Brody Condon 1999) o QQQ (Tom Betts 2002), que se recrean en los errores gráficos de figuras y scrolls (Betancourt 2017).

En Super Mario Clouds (2002), Cory Arcangel hackea un cartucho de NES (Nintendo Entertainment System) con el popular juego de plataformas Super Mario Bros (Shigeru Miyamoto 1985). Así, elimina todo rastro de figuración a excepción de cielo y nubes. Siguiendo esta misma línea rupturista, Arcangel hace una adaptación del juego Hogan's Alley (1984) en I Shot Andy Warhol (2002). En él parodia los valores relativos a la maldad y la bondad con una serie de rostros de la cultura popular: el papa de Roma, Flavor Flav (Public Enemy), Coronel Sanders y Andy Warhol -a quien se debe disparar para progresar en el juego-. Desde una postura humorística, el artista genera una apropiación que da lugar a una versión que evoca el intento de homicidio perpetrado por la activista Valerie Solanas al reconocido artista del pop art. Trabajos icónicos como los de Cory Arcangel permiten observar que, como afirman Clarke y Mitchell, «una señal de madurez creciente en el videogame art es que tiene un canon emergente de obras históricas y que estas forman puntos de referencia que informan el trabajo de otros artistas» $(2013,9)$. Los dos teóricos dilucidan así la noción de videogame art describiéndolo como un arte producido con videojuegos o influenciado por ellos de modo que los procesos de apropiación se detienen en su tecnología o su iconografía (2013, 10-12).

El colectivo JODI -formado por la pareja europea Joan Heemskerk y Dirk Paesmans- subvierte las convenciones de programas de ordenador e internet con modificaciones radicales de softwares originales. En sus manos, el lenguaje de los sistemas queda alterado para desestabilizar las imágenes mediante errores y los propósitos del juego a través de confusiones. En Jet Set Willy Variations C 1984 (2002) recuperan el juego Jet Set Willy (1984) para retocar su código y generar variaciones formales, textuales y cromáticas. Hacen lo propio con SOD (1999), una versión minimalista e irreconocible del juego Wolfenstein 3D (1992), donde el tono monocromático acerca los gráficos a la abstracción geométrica constructivista, mientras que los efectos sonoros señalan la violencia de la acción (Figura 8). Velvet-Strike (Anne-Marie Schleiner, Joan Leandre y Brody
Condon 2002) es un videojuego modificado, subtitulado «Counter-Military Graffiti for Cs», que propone realizar pintadas de graffiti en los escenarios del videojuego Counter-Strike (1999). La nueva versión invita a escribir consignas prediseñadas en las paredes que cuestionan tanto la violencia extrema del juego original como la guerra contra el terrorismo emprendida por George Bush. Otro trabajo reseñable de Joan Leandre es Retroyou_RC (1999-2001), en el que el prolífico artista catalán interviene el código del programa de un videojuego de automóviles dirigidos por control remoto. En la modificación desaparece la noción de gravedad, se tergiversa la realidad virtual y se convoca una abstracción audiovisual regida por el glitch digital. Visualizaciones hipnagógicas de impresiones alucinógenas determinan unas imágenes que acaban esquivando toda referencia figurativa.

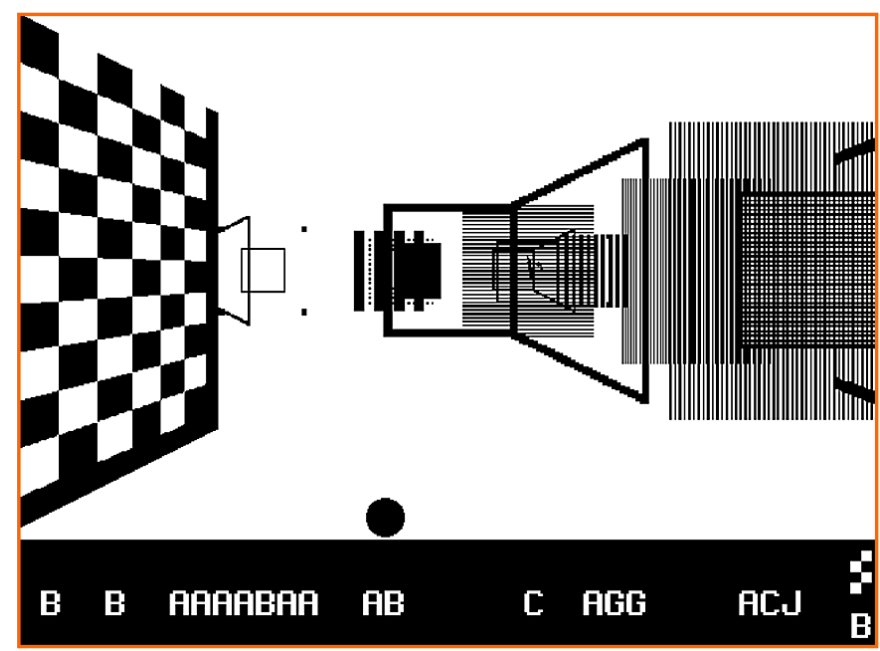

Figura 8. SOD (JODI 1999)

Fuente: @JODI

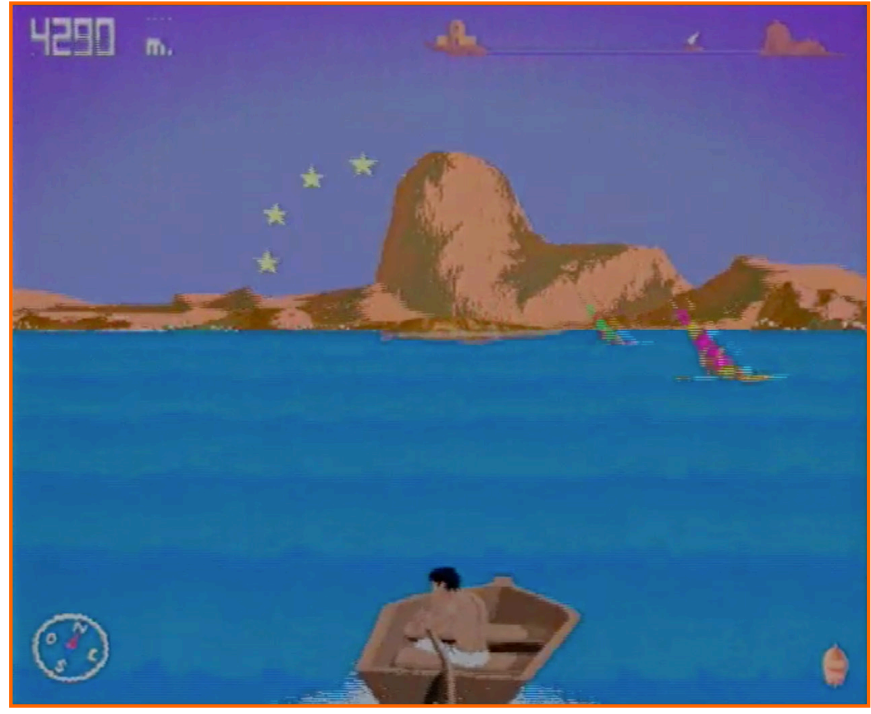

Figura 9. Estrecho Adventure (Valeriano López, 1996) Fuente: @Valeriano López 


\section{Crítica militar, parodia mediática y videojuego de artista}

El desarrollo de imágenes por ordenador para fines lúdicos coincide en el tiempo con las simulaciones del ámbito militar. Los simuladores de vuelo son el mejor ejemplo para visualizar cómo el desarrollo de una misma tecnología puede desembocar tanto en productos masivos para el entretenimiento como artilugios aptos para la enseñanza militar. Para Christiane Paul, «la historia tecnológica del arte digital está inextricablemente unida al ejército, a la industria y a los centros de investigación, así como a la cultura del consumo y a las tecnologías asociadas a ella, por lo que los juegos se consideran el ejemplo más representativo de un todo militar-industrial-lúdico» (2007, 37). Videoinstalaciones como Serious Games (Harun Farocki 2010) inciden sobre esta idea cuando desvelan la tecnología digital utilizada para simular escenarios de combate que sirven como entrenamiento para miembros del ejército de Estados Unidos. Farocki muestra la banalización de unas imágenes asépticas que, reproducidas por simuladores digitales, parecen amagar el terror y la violencia que se esconden tras ellas.

Fundamentado un posicionamiento adverso a la industria del entretenimiento se vislumbra el potencial político, económico y social de la cultura del videojuego. Formalizar instancias audiovisuales que visibilicen problemáticas que conduzcan a la movilización y la acción social es una manera de articularlo. Un trabajo como el vídeo Estrecho Adventure (Valeriano López 1996) representa el drama de la inmigración marroquí en el estrecho de Gibraltar en un soporte que le es inicialmente extraño (Figura 9). Continuas referencias a recursos visuales propios de videojuegos (vista cenital laberíntica tipo Pac-Man, videojuego de plataformas, simulación de trayecto en barca, etc.) convierten este vídeo monocanal es una propuesta crítica respecto a las políticas migratorias. Se subraya la ligereza icónica mientras se cuestiona el tratamiento dado por los medios de comunicación a este urgente tema.

Por su parte, una experiencia insólita de videojuego experimental como The Night Journey (Bill Viola 2007) evidencia el profundo interés que demuestra un reconocido videoartista por las posibilidades que ofrecen las nuevas tecnologías digitales en materia de jugabilidad. Mezclando opciones interactivas que simulan un punto de vista subjetivo de un personaje, el videojuego relata la búsqueda filosófica de la iluminación. Las imágenes que sustentan la narración son modificaciones -ralentizadas, desenfocadas y en blanco y negro- de grabaciones en vídeo de escenarios naturales procedentes del amplio archivo personal de Viola. Es un ejemplo de videojuego 3D (con modificaciones en su programación hasta el año 2018) realizado por un artista consagrado dentro del videoarte que decide experimentar con esta otra disciplina audiovisual desde su punto de vista personal.

Harun Faroki, Valeriano López y Bill Viola incorporan la iconografía de los videojuegos o implementan su tecnología, no para adentrarse en los entresijos de su industria, sino para expresarse artísticamente.
De este modo, proponen instancias personales que adquieren razón de ser dentro de unas trayectorias caracterizadas por desvelar valores ideológicos y vislumbrar búsquedas espirituales.

\section{Puesta en juego asíncrona}

Como vemos, la influencia recíproca entre el audiovisual experimental y los videojuegos resulta ineludible. En función de las diferentes etapas históricas estos influjos se decantan con mayor predominancia hacia un ámbito u otro. Ambas disciplinas hallan entresijos por los que se introducen recursos asociados normalmente a la otra. Si diversos cineastas se dejan seducir por las imágenes realizadas por ordenador, son muchos los videoartistas inmiscuidos en el poder de la interactividad. Pioneros de la animación abstracta por ordenador como John Whitney y Larry Cuba son tomados en consideración para solucionar gráficos de videojuegos, del mismo modo que artistas de la instalación como Jeffrey Shaw y Mary Flangan recurren al universo arcade para diseñar piezas interactivas exhibidas en contextos museísticos. Si los orígenes de los simuladores de conducción pueden rastrearse en filmaciones de trazo experimental, la machinima prosigue la tradición del cine de found footage y apropiación. Cineastas europeos como Zbigniew Rybczynski y Claude Leduch proponen puntos de vista subjetivos en planos secuencia que anticipan el desarrollo constante -sin cortes- de los juegos FPS. Otros videocreadores norteamericanos como Phil Solomon y Peggy Awesh deciden reciclar gráficos de videojuegos para darle la vuelta a sus planteamientos narrativos, ya sea desde la crítica feminista o mediante poéticas contemplativas. Los videojuegos modificados por artistas como Cory Arcangel y Joan Leandre rechazan la jugabilidad en favor de una postura disruptiva que busca en el error su razón de ser. Cineastas y videoartistas contrastados como Harun Farocki o Bill Viola se interesan por el mundo de los videojuegos para fomentar lecturas reflexivas que evidencien las contradicciones de sus utilidades 0 ensayan propuestas lúdicas de resonancias metafísicas.

Según Brett Martin, «los videojuegos se esfuerzan continuamente por convertirse en películas interactivas» $(2013,351)$. A pesar de la multiplicidad de planteamientos elaborados por programadores y diseñadores de videojuegos, es cierto que el cine sigue siendo un fuerte reclamo gracias a su verosimilitud y su narratividad. Pero si los videojuegos hallan conexiones con el cine experimental y la videocreación ya no es por sus parámetros argumentales, sino por sus exploraciones visuales y sus despliegues objetuales. En esta relación de reciprocidad la búsqueda de la interactividad adquiere protagonismo. Todas las manifestaciones artísticas mencionadas anticipan formalizaciones del universo lúdico del videojuego, investigan la riqueza de sus hallazgos o ensayan su complejidad para interrogar su potencialidad. Fomentar espíritus críticos y cultivar mentes abiertas que reconozcan la influencia ideológica que supone todo videojuego es el fin último de unas prácticas artísticas que generan debates alrededor de los valores morales y 
las cuestiones éticas que transmite todo videojuego. Una futura línea de investigación que se desprende de este artículo consiste en determinar qué películas, vídeos e instalaciones audiovisuales de contextos artísticos realizadas durante el periodo 2010-2020 pueden estudiarse bajo el prisma del videojuego. Dilucidar la relevancia de estos trabajos contemporáneos ayudará a seguir estudiando unos procesos dialécticos que ensanchan los horizontes artísticos, tanto del cine experimental y la videocreación como del videojuego.

\section{Referencias bibliográficas}

Alsina, Pau. «Nodo Jugabilidad: arte, videojuegos y cultura». Artnodes, 7 (2007). D0l: https//dx.doi.org/10.7238/a.v0i7.760.

Betancourt, Michael. Glitch Art in Theory and Practice: Critical Failures and Post-Digital Aesthetics. Nueva York: Routledge, 2017. D0l: https://doi.org/10.4324/9781315414812.

Bogost, lan. Persuasive Games. The Expressive Power of Videogames. Cambridge: The MIT Press, 2007. D0I: https://doi.org/10.7551/ mitpress/5334.001.0001.

Bonet, Eugeni. El cine calculado. Ciclo de cine y vídeo. Madrid: MNCARS, 1999.

Clarke, Andy y Grethe Mitchell (Ed.) Videogrames and Art. Second edition. Bristol: Intellect, 2013.

Flanagan, Mary. Critical Play. Radical Game Design. Cambridge: The MIT Press, 2009. D0l: https://doi.org/10.7551/mitpress/7678.001.0001.

Galloway, Alexander R. Gaming. Essays on Algorithmic Culture. Minneapolis: University of Minnesota Press, 2006.

Gunning, Tom. «The Cinema of Attraction: Early Cinema, its Spectator and the Avant-Garce». Elsaesser, Thomas y Adam Barker (ed.) Early Cinema: Space, Frame, Narrative, 56-62. Londres: BFI, 1990. D0I: https://doi.org/10.5040/9781838710170.0008.

Horwatt, Elijah. «New media resistance: machinima and the avant-garde». CineAction, 73-74, (2007).

Kallay, Jasmine. Gaming Film: How Games are Reshaping Contemporary Cinema. Londres: Palgrave MacMillan, 2013. D0I: https://doi. org/10.1057/9781137262936.
Lebihan, Yann. Historia de los videojuegos. Barcelona: Robinbook, 2018. LeGrice, Malcolm. «Fatum, protagonía y el síndrome Zap Splat. Algunos conceptos teóricos para un cine interactivo». Giannetti, Claudia (ed.) Arte en la era electrónica. Perspectivas de una nueva estética, 46-52. Barcelona: ACC L'Angelot, 1997.

Lipovetsky, Gilles y Jean Serroy. La pantalla global. Cultura mediática y cine en la era hipermoderna. Barcelona: Anagrama, 2007.

Martin, Brett. «Should Videogames Be Viewed as Art?». Clarke, Andy y Grethe Mitchell (ed.) Videogrames and Art. Second edition, 345356. Bristol: Intellect, 2013.

Rellie, Jemima. «Feedback / Feedforward». Feedback: Arte reactivo a instrucciones, a inputs o a su entorno. Catálogo de exposición. Gijón: Laboral, Centro de Arte y Creación Industrial, 2007.

Paul, Christiane. «Feedback: del objeto al proceso y sistema». Feedback: Arte reactivo a instrucciones, a inputs o a su entorno. Catálogo de exposición. Gijón: Laboral, Centro de Arte y Creación Industrial, 2007.

Salen, Katie y Eric Zimmerman. Rules of Play: Game Design Fundamentals. Cambridge: The MIT Press, 2003.

Schrank, Brian. Avant-garde Videogames. Playing with Technoculture. Cambridge: The MIT Press, 2014. D0I: https://doi.org/10.7551/ mitpress/8132.001.0001.

Sharp, John. Works of Game: On the Aesthetics of Games and Art. Cambridge: The MIT Press, 2015.

Wees, William C. Recycled Images. The Art and Politics of Found Footage Films. Nueva York: Anthology Film Archives, 1993.

Weibel, Peter. «Realidad virtual: el endoacceso a la electrónica». Gianneti, Claudia (ed.) Media Culture. Barcelona: L'Angelot, 1995.

Wooster, Ann-Sargent. «Reach Out and Touch Someone: The Romance of Interactivity». Hall, Doug y Sally Jo Fifer. Illuminating Video. An Essential Guide to Video Art, 275-303. Nueva York: Aperture, 1990. Youngblood, Gene (1970) Expanded Cinema. Nueva York: E.P. Dutton \& Co. Inc. Edición en español: Cine Expandido (2012) Buenos Aires: EDUNTREF. Universidad Nacional de Tres de Febrero. 


\section{artnodes}

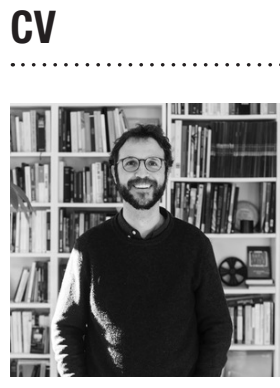

\section{Albert Alcoz}

Universidad de Barcelona

albertvinasalcoz@ub.edu

Albert Alcoz (Barcelona, 1979) es cineasta, investigador y programador de cine experimental y videocreación. Profesor asociado del Departamento de Artes Visuales y Diseño de la Facultad de Bellas Artes de la Universidad de Barcelona. Doctor en Teoría, Análisis y Documentación Cinematográfica por la Universidad Pompeu Fabra de Barcelona, con una tesis doctoral sobre el sonido y el cine estructural (2016). Licenciado en Bellas Artes por la Universidad de Barcelona (2001) y máster de Cine Documental de Creación por la Universidad Pompeu Fabra (2005). Ha escrito los libros Resonancias fílmicas. El sonido en el cine estructural (1960-1981) (Shangrila, 2017), Radicales libres. 50 películas esenciales del cine experimental (UOC, 2019) y Música esporádica (Breus. CCCB, 2021). Colabora habitualmente con la plataforma de audiovisual experimental HAMACA, el festival de vídeo L00P y Xcèntric, el cine del CCCB.

http://www.albertalcoz.com/

https://orcid.org/0000-0003-2657-0581 